\title{
On Cultivation of Students' Ability in Innovation and Practice in Vocal Music Teaching
}

\author{
Hong-xia Xu \\ School of Music, Linyi University, Shandong, China
}

\begin{abstract}
Vocal music teaching is an emotional experience teaching art. It involves cultivating both students' pronunciation skills and the ability to express the rich connotation of the song through the training of sound production. The era of knowledge economy in twenty-first Century, which is marked by knowledge and technology innovation, puts forward higher requirement for the teaching reform of college music majors. To complete the training of music talents with innovative consciousness and innovative ability, it is imperative to put innovative education as the key point in the implementation of quality education, combine the theory with practice better, and apply it to the training of college students' comprehensive practice ability.
\end{abstract}

Keywords - vocal music teaching, the ability of innovation and practice, cultivation

\section{声乐教学中学生创新实践能力的培养}

\author{
绪红霞 \\ 临沂大学音乐学院, 临沂, 山东, 中国
}

\begin{abstract}
摘 要 声乐教学是一门情感艺术, 它不仅是培养学生的发音技巧, 还要通过发声的训练表达丰富的歌曲内涵, 对于 21 世纪以 知识创新和技术创新为新特征的知识经济时代, 这对于高校音乐专业的教学改革提出了更高的要求。要完成培养适应时代要求的具有 创新意识和创新能力的音乐教育人才, 当务之急是必须把实施创新教育作为实施素质教育的着力点和突破口, 把理论与实践更好的结 合并运用到大学生综合实践能力培养中。
\end{abstract}

关键词 声乐教学, 创新实践能力, 培养

\section{1. 教师教学观念的转变}

美国教育学家克罗韦尔 $(\mathrm{S} \cdot \mathrm{Crowell})$ 指出: “教育面 临的最大挑战不是技术, 不是资源, 不是责任感, 而是去 发现新的思维方式。”高校教师不是保姆, 也不能仅仅作为 本专业的行家里手, 还要学生创造性地提出问题, 并引导 学生解决问题。这就要求教师改变传统 “授——受” 式传 统教学向 “学习者” 的教学观转变, 使学生 “学会学习”。

在过去相当长的时期内, 声乐课堂教学以知识传授为 主, 以培养学生掌握已有教材内容为主要目标, 学生学习 成绩与听课质量挂钩, 被动接受知识。这种教学方式培养 出来的学生大多只会盲目的模唱, 缺乏融会贯通的能力和 实际应用能力。体现在声乐教学中, 学生只是学会教师教 授的几首作品, 而对于相关知识如伴奏、作曲家、作品创 作背景、不同声部的了解等知之甚少, 学习方法上不敢越 雷池一步, 这种磨灭了学生自主创新能力, 单一僵化的教
学观念和方式方法, 严重压抑和阻碍了学生的自主意识、 个性发展、创新意识以及与他人团结协作意识的培养和发 展。

\section{1 更新教育观念，培养创新意识}

随着创新教育的深入，声乐教师首先要改变多年来习 以为常的教学方法习惯, 放弃以自我为中心等权威意识, 将创新教育的思想和方法落实到日常课堂教学之中; 教师 要从知识的传授者转为学生学习的指导者, 不但要给学生 传授书本的知识, 更重要的是引导学生对未知领域的探索, 让学生自己探寻解决问题的方法。教师要充分地尊重信任 学生, 对每一个学生抱有真诚的期望, 充分发挥学生主动 学习能力和解决问题的能力, 使学生在演唱作品的过程成 为二度创新的过程, 使课堂教学过程成为师生共同参与、 
共同探求知识的过程, 以创新教育为目标的学习过程。这 就要求教师要从根本上转变教育观念, 不断强化创新意识, 提高创新素质, 从而为学生创造性潜能的发挥创设良好的 环境。

美国著名教育家拿破仑 - 希尔曾说: “信心是心灵的第 一号化学家, 当信心融合在思想里, 潜意识会立即拾起这 种震䛜, 把它变成等量的精神力量, 再转送到无限智慧的 领域里促进成功思想的物质化。” 因此, 培养学生歌唱中的 创新意识最重要的一点就是给学生以充分的自信, 即促使 学生发现自我, 修炼自我, 超越自我, 投身歌唱, 也就是 在一开始教学生起步时, 就让学生处于一种最舒服自然的 状态, 唤起他们歌唱的从容自信的心态, 从而获得感受自 我品质和创新意识的动力, 为声乐课堂的教学成功奠定良 好的基础。

\section{2 强化心理素质, 突出个性培养}

现代科学认为, 学生求知、发展和成才, 是一种持续 不断的心理活动和心理发展过程。人的心理发展是由智力 因素和心理驱动与制约系统构成的统一的心理发展系统。 从学生求知发展的整体目标和体系来看, 学生的品德、文 化、身体、审美、劳动、心理乃至于创新等方面的素质是 相互促进、相互制约的, 心理素质是其他素质发展的中介 和基础。尼采曾经说过, “个性弱的人没有超越自己的能 力”, 不能超越自己, 则无创造可言。追求个性和自由的人, 往往具有很强的创新意识和独创能力, 创新在本质上就是 追求新意和差别。而创新人格是一个人进行创新、发明的 基础, 是创造者必备的、良好的、持久的个性品质。可以 说, 教育的最终目的不仅是传授已有的东西, 而是要把作 为人的独特本质的创造精神引发出来, 使其成为能够自觉、 自由创造的人。因此, 培养学生良好的心理素质和个性特 质, 是实施创新教育的重要一步。

声乐课堂教学直接的任务是训练人声, 提高人声的艺 术表现能力, 训练的着眼点在于通过调整、协调人体发声 器官, 使其发声的动作日殝完善。但是不管练唱的内容, 还是演唱的形式都没有离开表现人的思想感情, 没有脱离 演唱的情趣。也就是说, 只有演唱者具备良好的心理素质, 演唱的技能才能正常发挥。歌唱是受人的情感、情绪、兴 趣、性格等心理因素所左右。因此, 声乐教学必须把心理 素质纳入人声的训练之中, 指导学生调控好歌唱心理, 克 服学生对高音的恐惧感, 对技术的神秘感和对演唱舞台的 陌生感等种种心理障碍, 从而为自己声乐表演艺术和声乐 教育艺术的提高打下基础。

注重学生音乐审美心理的培养和提高是搞好声乐课堂 教学的前提。优秀的歌唱者无不声情并茂。因为只有具有
良好的音乐审美心理, 才能准确、深刻、细致地体验音乐 作品的情感内涵。通过感觉、体验、联想和理解, 使学生 在欣赏中自觉不自觉地对音乐作品进行再创作, 用自己对 生活的感悟和接触的现实社会, 理解把握音乐作品, 在演 唱时更富有个性特色。

富有个性的音乐演唱是走向成熟的标志。要善于启发 学生对自己演唱的作品有清醒的自我意识, 并且能根据自 身的声音条件和演唱风格, 找到最适合自己的表演方式, 形成独特的个人演唱风格, 如: 新风霞、常香玉、郭兰英、 彭丽媛、张也同是演唱民族歌曲, 但却各有特色, 才能使 同一部音乐作品获得不同的艺术表现, 而这正是音乐作为 一种表演艺术所具有的独特魅力之所在。

\section{2. 改革教法学法, 培养创新思维}

适应高等教育目标的要求, 高校教师不仅是本专业的 一个行家, 还要担负起起创造性地提出问题, 并引导学生 解决问题。教师要教育学生学会认知、学会辨别, 教会学 生在不同文化思想交流中产生自己健康的思想。在并不遥 远的将来, 高等教育将真正成为为人们提供终身教育的机 构。在现代信息技术的推动下, 未来高等教育的图景是全 新的。大学将成为人们获取知识、提高素质、增强竞争能 力的重要场所。这一切说明, 不仅大学教师的思想需要不 断更新, 课堂教学模式也要随着现代教育技术的发展而不 断改进, 以适应高等教育不断发展的内在要求。

声乐教学是一门情感的艺术, 它不仅要培养学生的发 音技巧, 更重要的是通过发声的训练表达丰富的歌曲内涵。 而教师对于学生的热爱, 能在教师和学生中形成一种依恋 性的情感体验, 教师对学生殷切的希望和暗含的期待, 可 以产生巨大的感召力, 从而促使学生智力、情感和个性的 发展, 为教师在声乐教学中使学生情感内化成为可能。教 师在教学过程中应充分利用声与情的关系, 用通俗易懂的 生动语言、活泼生动的形象比喻启发学生, 并辅以范唱、 手势等; 教学语言精炼、艺术、富有情感, 结合面部表情、 眼神、形体动作等可产生良好的示范效果, 培养学生歌唱 的欲望, 创造美好的演唱艺术形象。

\section{1 教师的创新性授课模式}

教师教授过程中也应具备创新性, 一般教师在教学过 程中大多强调学生听话、服从, 学生的一些新的观点, 新 的思考由于与教师的教学目标不一致而被打入 “冷宫”, 忽 视学生的创造力、逆向思维的训练, 学校所培养的人才可 以说是一种 “继承式” 人才, 而不是创造性人才。

创新性教师在教学过程中, 采用多种教学组织形式相 结合的办法, 有目的的设障立疑, 开拓思路, 启发诱导, 
充分调动学生学习的积极性和创造性, 不以某种 “正确答 案” 为满足, 而应让学生自己设计解决问题的方案, 鼓励 个体 “原则” 的形成。

创新思维可以使人产生全新的想法, 教师首先要尊重 学生的个性, 承认学生个人的兴趣和性格的多样性, 让学 生在教师引导下, 积极主动地进行思维和学习, 独立地探 索和总结出一套适合自己的学习方法, 达到学会和会学的 目的。在声乐课堂教学中利用音乐艺术作品的独特鬼力, 设法激励学生的创新思维是搞好课堂教学的关键。作为以 有规律的声音旋律为特征的音乐, 以其声音的强弱和走向 来不断地感染、启发学生学习兴趣, 进而激发学生的好奇 心, 让学生和老师一道去感受, 去分析某概念或某一定义 及其在音乐中的作用, 使学生既做扮演者, 又做欣赏者, 同时又是一名探索者和发现者。教师根据学生的嗓音条件, 因材施教, 遵循由浅入深、循序渐进、理论知识与实践相 结合的原则, 采取个别授课、声乐小组辅导、登台演唱观 摩等方法, 逐步提高学生的演唱能力、艺术修养、艺术感 受力, 从而培养学生在音乐学习中的创造能力。

\section{2 学生学习过程的主动性}

传统教学模式大多以 “满堂灌”、“一言堂”, 注重死记 硬背, 学生对学习动机不明确, 大多为应付考试而学, 学 生丧失了学习的积极性与主动性, 毫无学习兴趣和热情, 而且容易形成心理疾病和障碍, 掌握知识、发展能力只能 成为一种虚无的假设。而创新性教师会在宏观指导下充分 发挥学生的自主能动性, 要求学生以主动探索的方式不断 地加工和改造已有的信息和材料, 达到对知识间相互关系 的理解, 全面深入地掌握知识、发现真理, 改变过去那种 用 “正确逻辑” 统治头脑而使头脑成为 “单向道” 的状况。

正如声乐授课过程中, 改变以往单纯的老师教学生模 仿的模式, 让学生在学习过程中作为主体, 主动出击, 让 学生结合自身所学, 提出疑难问题, 尝试给出答案, 教师 适当纠错, 在教与学结合一体的过程中, 让学生掌握课堂 主动权, 主体导向, 更好地掌握声乐演唱的方法技巧。另 外, 通过观摩、参与舞台演出学习、总结经验, 提高自身 专业素养, 让学生充分发挥主导性、自体性、团体性、创 新性。

国际 21 世纪教育委员会向联合国教科文组织提交报 告——《教育——财富蕴藏其中》指出: 21 世纪最成功的 劳动者将是最全面发展的人, 是对 “新思想和新机遇开放 的人”。这种全面发展的人应该具备 “四个学会”, 即学知、 学做、学会共同生活、学会生存。它回答了 21 世纪教育遇 到的挑战和应遵循的发展模式。因此我们应清醒地认识到, 在声乐课堂教学中实施创新教育才是深化音乐教学改革的
必然选择。只有彻底更新教育观念, 改变旧的教育模式, 变 “接受性教育” 为 “创新性教育”, 变 “接受性学习” 为 “创新性学习”, 才能真正建立创造性人才的培养机制, 高 校音乐教育也才能实现其创造型音乐教育人才的培养目 标。

\section{3. 利用现代教育技术, 使学生通过多种渠道获得更 多地体验, 提高教学的信息量。}

加强声乐教学的实践性能够使单一传授知识的过程变 为知识情感态度等统一发展的过程, 这与传统单一传授知 识的教学相比无疑是一种创新。再者, 实践活动是创新的 基础, 加强声乐教学的实践环节可促进声乐教学的创新, 而由单纯声乐知识的传授向重视声乐教学实践环节的转变 已成为当前声乐教学改革的方向。

临沂大学音乐学院在声乐教学实践性方面做到了饯行 实际, 每学期均有学生、教师组织的多场次实践型声乐演 唱音乐会。在优良的教学环境, 先进的教学配套设施下, 教师、学生自觉自发地举办音乐会, 充分发挥个人所长, 不但增长了个人、集体的舞台经验, 同时也对学生心理、 生理、实践能力等多方面进行综合培养。通过舞台实践培 养, 学生改变以往胆小、怯场、紧张等多方面不利因素, 从容、自信、端庄、赋予感情的演绎歌曲内涵, 甚至很多 学生在校期间积极参加各种国家级、省级、市级等比赛, 名列前茅; 诸如这些都是对学生综合实践能力培养的饯行, 从多方面激发学生学习的积极性, 学校培养的不再是 “机 器人” 式的统一模式的书呆子, 而是具备综合实践能力的 高素质、高水平的人才。

在不远的将来，高等教育重视的已不是信息本身，而 是篮选、精炼出人们需要的信息; 大学将真正成为人们提 供终身教育的机构。在现代信息技术的推动下, 大学将成 为人们获取知识、提高素质、填充力量、增强竞争能力的 重要场所。

\section{参考文献(References)}

[1] Xu Hongxia. Confuciu's "Happy Teaching" and Its Enlightenment on Teaching Music. Contemporary Education Science, 2003.[13]

[2] $\mathrm{Xu}$ Hongxia. On Pronunciation Skills and Emotional Expression in Vocal Music Teaching Shandong Education Scientific Research, 2000.[9]

[3] Xu Hongxia. On the Implementation of Innovation Education in Vocal Music Teaching Class Journal of Linyi Normal University, 2003.[25]

[4] Xu Hongxia. Quality Education Calls for Innovative Teachers. Shandong Education Research, 2001.[7, 8]. 